\title{
Hrd Climate Survey in Selected Public Sector Bank (Uco Bank)
}

\author{
Dipak Kumar Gupta ${ }^{1}$, Dr. Kalyan Kumar Sahoo ${ }^{2}$, Dr. Ayasa Kanta Mohanty ${ }^{3}$. \\ 1. Research Scholar Siksha 'O' Anusandhan University, Khandagiri, Bhubaneswar, Odisha, India. \\ 2. Professor Mahendra Institute of Management \& Technological Studies (MIMTS), Bhubaneswar, \\ Odisha, India. \\ 3. Associate Professor Institute of Business \& computer studies (IBCS) Siksha' O' Anusandhan \\ University, Bhubaneswar, Odisha, India
}

\begin{abstract}
In the present day banking affairs lots of issues are emerging the customer satisfaction are followed by different private banks aiming at replacing the existing banking scenarios

The effective performances of the human resource depends on the type of HRD climate that prevails in the organization, if it is good then the employee's performance will be high but if it is average or poor then the performances will be low. The study of HRD climate is very important for all the organizations, specially in Banks a service sector, when there is a stiff competition and presence of financial recession.

The present study of HRD climate is a purposeful attempt to find out the type of HRD climate prevailing in UCO Bank a Public Sector Bank in Bhubaneswar, Odisha.

The researcher had collected data from UCO Bank Bhubaneswar from officers MM-III and MM-II using structured HRD climate questionnaire. The data was analyzed using various statistical tools such as mean, standard deviation, percentile. A minimal positive development climate is essential for the success of the programmes like performance appraisal, counseling, O.D, potential appraisal. Job enrichment introduced in various organizations. The survey is to find out the extent to which such development climate exist in the organization.
\end{abstract}

Key word: HRD Climate Survey in Public Sector Bank (UCO Bank)

\section{Introduction}

The liberalization in banking operations is bound to create a favourable climate for the growth of the economy and banking in the state of Odisha. Bank's may have to throw away the traditional banking procedures and make themselves fit to face the technological explosion entering into the banking industry. The way of dealing with customer has changed the patterns of working hours and even offices are accessed from home in the new strategy and policy being proposed information technology and support system. How does human resources play an important role in human resources development? You might as well as ask and soon enough will answer that yes, it plays a great role in developing human resources.

Organization become dynamic and growth orientated if their people are dynamic and proactive. Every organization can do a lot to make their people become dynamic and proactive through proper selection of such people and nurturing their dynamisms and other competencies. Organization cannot survive beyond a point unless they are continuously alert to the changing environment and continuously prepare their employees to meet the challenges and have an impact on the environment". Thus HRD is an essential process for organization survival and growth. An optimal level of a developments climate" is essential for facilitating HRD. Such a climate is characterized by the following tendencies.

* A tendency at all levels and specially top management to treat people as most important resource.

* A perception that developing competencies in the employee is the job of every Manager/Supervisor.

* Faith in the capability of people to change and acquire new competencies at any stage of life.

* A tendency to be open communication.

* A tendency to be encourage risk taking.

* A tendency to help employees recognize their strength and weakness.

* A general climate of trust.

* A tendency on the part of employees to be generally helpful to each other and collaborate.

* Team spirits

* A tendency to discourage favouritism and biases.

* Supportive personnel policies.

* Development oriented appraisal, training, reward, job rotation, career planning and potential appraisal. The organization differ in the extent to which they show this tendency. Some organization may have only a few 
of these tendencies and few others. Prof. T.V. Rao and E. Ibraham of XLRI, Jamshedpur has developed an instrument than is widely being used to survey the HRD climate.

\title{
II. Objective Of The Study:
}

* To study the type of HRD climate prevailing in UCO Bank, Bhubaneswar, Odisha, India a public sector Bank.

* To study the impact of mechanism like performance appraisal, potential appraisal, career planning, performance rewards feedback etc on manager.

* To Study how openness is effective when employees feel free to discuss the ideas, activities and feelings with each other.

* To study the need of various training programmes to improve the knowledge and competencies of mangers.

* To study the importance of Job rotation amongst the mangers which is essential to enrich knowledge.

\section{Sample Design:}

Sample size has been take as 100 people from (Manager MM-III \& MM-II). So total score of all 38 questions from each sample (person) is calculated. The average score of 100 people is used a basis for taking any conclusion. Like wise score of sample 1. is 52; sample 2 is 103, Sample 3 is 90 ; sample 4 is 92 and So on.

\author{
Summation of scores of 100 people$$
100
$$$$
8425 / 100
$$$$
=\quad \text { Average score }
$$ \\ So in our case it is 84.25
}

Since the score is below 114 thus we can say that HRD climate is not good, but since it is above 76 thus even we can not say there is a considerable scopes of improvement. So we conclude that in "UCO" there is fair HRD climate and there can be some improvement in HRD climate possible.

These 38 items assess:

* OCTAPAC culture

(Openness, Confrontation, Trust, Autonomy, Proaction, Authenticity and Collaboration)

Culture is essential for facilitating HRD. Openness is there when employees feel free to discuss their ideas, activities and feelings with each other. Confrontation is bringing out problems and issues into the open with a view to solving them rather than hiding them for fear of hurting or getting hurt. Trust is taking people at their face value and believing what they say. Autonomy is giving freedom to let people work independently with responsibility. Pro-activity is encouraging employees to take an initiative and risks. Authenticity is the tendency on the part of people to do what they say. Collaboration is to accept inter dependencies, to be helpful to each other and work as teams.

- Implementation of HRD mechanism

Successful implementation of HRD involves an integrated look at HRD and efforts to use as many HRD mechanisms as possible. These mechanisms include: performance appraisal, potential appraisal, career planning, performance rewards, feedback and counseling, training, employee welfare for quality work life and job rotation.

\section{- General Climate}

A general supportive climate is important for HRD if it has to be implemented effectively. Such supportive climate consists of not only top management, line management's commitment but good personnel policies and positive attitudes towards development.

\section{Methodology}

The questionnaire uses a five point rating scale. It could be administered to all employees (Specially Supervisory and managerial staff) and a HRD climate profile can be drawn up. These Scores may range from *38-190) when the scores on all 38 items are added to get a composite score.
* Scores above 114 indicate "a good HRD climate.
* Scores Near to 150 indicate "excellent HRD climate"(rare)
* scores below 76 "there is considerable scope of improvement"

\section{Analysis : \\ PHASE-I}

The "5 points rating scale" used is as following 


$\begin{array}{lll}5 & = & \text { Almost always true } \\ 4 & = & \text { Mostly true } \\ 3 & = & \text { Sometimes true } \\ 2 & = & \text { Rarely true } \\ 1 & = & \text { Not at all true }\end{array}$

PHASE-II.

Now we will analyze each of 38 questions individually to find out the area where improvement is possible. First calculated average then $\%$ by using formulae

$\%=($ Mean Score -1$) \times 25$

\section{Question No.1}

"Average Score" to this question is $2.7 \$$. => Thus this is "mostly true". The top management is not concerned about the each that employees are not enjoying their work. One way out is to go for "potential appraisal" 80 that right person (according qualification, preference choice) should be given right job. Another way out "job rotation".

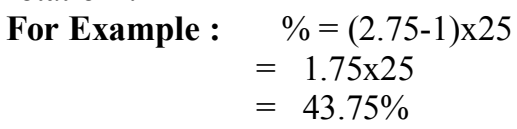

$$
=43.75 \%
$$

\section{Question No.2}

"Average Score" to this score is (1) $\Rightarrow>$ Thus this implies "Rarely True". The top management does not believe than human resource are not an extremely important and that they does not have to be treated. Because the conceptualization of implementing HRD progress is that Ist management has to treat human resource more humanity. $(0 \%)$

\section{Question No.3}

"Average Score" to this is $2.75 \Rightarrow$ mostly true development of subordinates are not seen as important part of their job by the mgrs. /officers here. Because of this the mgrs are always concerned with their routine job and never allow themselves to think about any development of work for personnel.(43.75\%)

\section{Question No.4}

"Average Score" to this question $(1.75)=>$ Sometimes true

It is very rare that personnel policies support/facilitates employees development. So the company should go for some programmers for personnel development like career development, career planning etc.(19\%)

\section{Question No.5}

"Average Score" to this question is $1.25 \Rightarrow$ rarely true.

The top management is not willing to spend a considerable amount of time and resources for development of employees. This is really a serious problem. Because no HR programme can be carried out if top management is not have the vision of Human resource development. The one way out is top management should go for comparative study of organization development where HR programs are successfully implemented.(6.25\%)

\section{Question No.6}

"Average Score" to this question is $1.75=>$ sometimes true.

Senior employee/executives rarely take active interest to help juniors in learning their jobs. Thus a climate segregation while collars is there, which must be removed for any successful HR programme. (19\%)

\section{Question No.7}

"Average Scores" to this question is $1.25=>$ rarely true.

People lacking competence are not at all helped to acquire competence but rather left unattended. This makes a increasingly inefficient workforce, having low morale of doing work and not at all interested for self as well as organizational growth. Also, frustration arises from this approach. This is serious problem.(6.25\%)

\section{Question No.8}

"Average Score" to this question is $1.5 \Rightarrow$ Sometimes true.

"Mgrs." do not believe that employees behaviour can be changed and people can be developed at any stage of their life. This is totally wrong perception, people can be always motivated to learn if they see that there is some growth in their career with a bit of even increases in earning. Due to this negative attitude the mangers have built a negative image of their employee, which can be removed only by getting some positive 
result by HR programme or by visiting organization where HR programs have brought this type of change. $(12.5 \%)$

Question No.9:

"Average Score" to this question is $3.25 \Rightarrow>$ Mostly true

This is really a good picture of good industrial harmony/rest at "UCO banks" So HRD programs can be implemented with a bit case. $(56.25 \%)$

\section{Question No.10:}

"Average Score to this question is $3.75 \Rightarrow$ Almost always true

Employees have informal relationship with superiors and do not he sestets in discussing personal problems with them. This is a positive sign. (68.75\%)

\section{Question No.11:}

"Average Score" to this question is $1.5 \Rightarrow$ Sometimes true.

The psychological climate in this organization is rarely conducive to any employee interested in developing himself by acquiring new knowledge and skills.(12.5\%)

\section{Question No.12:}

"Average Score" to this question is $2.75 \Rightarrow$ mostly true.

The seniors many times true in respect that they prepare juniors for future responsibilities. But this approach is very personal. Whereas by successfully implementing HRD policies, such as career planning this can be done more efficiently.(43.75\%)

\section{Question No.13:}

"Average Score" to this question is $1.25=>$ rarely true.

Top management of this organization do not makes any effort to identify and utilize the potential of employees. So there is least application of "Potential Appraisal"(6.25\%)

Question No.14:

"Average Score" to this question is $2.5=>$ Sometimes true.

Sometimes promotion is based on suitability of candidate otherwise favoritism. There is a negative aspect in organization that is favoritism; this has to remove by "Potential appraisal". (37.5\%)

\section{Question No.15:}

"Average Score" to this question is $2.75 \Rightarrow$ mostly true.

reward system is there is organization for good work. But it is not very successful since few good workers remains unattended (i.e. not given reward) and develop negative morale in them.(43.75\%)

\section{Question No.16:}

"Average Score" to this question is $1.5 \Rightarrow$ Sometimes true When an employee does good work supervising officer not always, take good cares to appreciate of. This is a serious problem because every employees cannot be given rewards but at least a few words of appreciation can really boost up one's morale high.(12.5\%)

\section{Question No.17}

"Average Score" to this question is $1.5=>$ Rarely true. "Performance appraisal" reports are mostly based on favoritism and not on objective assessment.(12.5\%)

\section{Question No.18}

"Average Score" to this question is $2.5 \Rightarrow$ Sometimes true. Most people in the organization have fixed impression about each other. This is a sort of "Closed mind" attitudes. This has to be removed.(37.5\%)

\section{Question No.19}

"Average Score" to this question is $1.75 \Rightarrow$ Sometimes true.

Employees are never insisted on innovativeness, creativity. This lead to boredom and monetary in job thus work became very routine. $(19 \%)$

\section{Question No.20:}

"Average Score" to this question is $2.75=>$ Mostly true.

Punitive measures are very less, rather it employees makes a mistakes his supervisors treat it with understanding and help him learn from such mistakes. This is a good sign. (43.75\%) 


\section{Question No.21:}

"Average Score" to this question is $1.75=>$ Sometime true.

Sometimes weakness of employees are communicated in threading way so this may generate a sense of fear in employees mind.(19\%)

\section{Question No.22:}

"Average Score" to this question is $2.5=>$ sometime true.

Behavioral feedback given to the employees are not always used for this development.(37.5\%)

\section{Question No.23:}

"Average Score" to this question is $0.75 \Rightarrow$ rarely true

Employees are never helped by supervisory officer to evaluate his strength and weakness. Thus it is very difficult for one to evaluate about own, unless evaluated by supervisors. (-6.75\%)

\section{Question No.24:}

"Average Score" to this question is $2.75=$ mostly true. Employee take their training seriously if they are assigned for the same.(43.75\%)

\section{Question No.25:}

"Average Score" to this question is $1 \Rightarrow$ rarely true.

After giving training the employees are never given chance to apply them. Thus the time, resource is getting wasted as well a negative attitude toward training and low morale work cultures is developing. $(0 \%)$

\section{Question No.26:}

"Average Score" to this question is $3=>$ mostly true training is given to the employee according to training need identification that implies training is needed in that instant. But the outcome of such training case be only evaluated if employees are given chance to apply them. $(50 \%)$

\section{Question No.27:}

"Average Score" to this question is $2.5 \Rightarrow$ Sometime true. Many people trust each other in organization. It means team, or group task can be easily framed. Team spirit can be easily developed.(37.5\%)

\section{Question No.28:}

"Average Score" to this question is $3.75 \Rightarrow$ Almost always true.

Junior employees are not afraid to discuss their feedings with supervisors, thus their is a open culture exist in the organization. $(68.75 \%)$

\section{Question No.29:}

"Average Score" to this question is $2.75=>$ mostly true. Superior employee do express their feeling to subordinates but not equivalent to those as subordinates to superiors.(43.75\%)

\section{Question No.30:}

"Average Score" to this question is $1.25 \Rightarrow>$ rarely true. It very rare that employee take initiative without instructions from supervisors. This implies very classical approach of management is prevailing there. $(6.25 \%)$

\section{Question No.31:}

"Average Score" to this question is $2.25 \Rightarrow$ Sometimes true.

"Delegation of authority" is very rare in this organization.(31.25\%)

\section{Question No.32:}

"Average Score" to this question is $3.5 \Rightarrow$ mostly true.

If employees (jr.) get authority from Senior then he take is as opportunity for development. So, authority must be delegated. $(62.5 \%)$

\section{Question No.33:}


"Average Score" to this question is $3.25 \Rightarrow$ mostly true. It is the "Team Spirit" which ultimately add up to group task, Team building, These two are prime basis for installing HRD programme and policies. $(56.25 \%)$

\section{Question No.34:}

"Average Score" to this question is $3.5 \Rightarrow$ mostly true. "Average Pulling" is comparatively low at 'UCO" So, the work culture there is cooperating, atleast at the some level, if not to Superior-Subordinate So, this is going to be supportive for implementing HRD programmes. $(62.5 \%)$

\section{Question No.35:}

"Average Score" to this question is $2.5 \Rightarrow$ Sometimes true. It is very rare that career opportunities are provided by Seniors to subordinates, So Seniors are not concerned about career development of junior staff. $(37.5 \%)$

\section{Question No.36:}

"Average Score" to this question is $2.75 \Rightarrow$ Sometimes true. The future plan/programme are never discussed so generally among different levels of management. So the overall approach to go forward to such planning is always adverse for them. Thus UCO management most go for better communication system by right procedures and balancing formal and informal relationship.(43.75\%)

\section{Question No.37:}

"Average Score" to this question is $2025 \Rightarrow$ Sometimes true. Through "Welfare of employees" are carried out at UCO but then also it is not well organised and planned according to census. So they most have to review their personnel function regularity to take care of this problem. Moreover HRD facilities would further help these welfare programmes. $(31.25 \%)$

\section{Question No.38:}

"Average Score" to this question is $1 \Rightarrow$ Rarely true. This implies "job rotation" is very rarely done for the development of the employee. This is also need to take case of personnal function of UCO.(0\%)

\section{Summary :}

After analyzing the questions individually and taking average of them and summing up all those we get total 89.25 , which is equal to score of phase I".

\begin{tabular}{|c|c|c|c|}
\hline \multicolumn{4}{|c|}{ Item-Wise "Means" \& "Percentage" Of The Total Sample(Uco) } \\
\hline Q. No. & Mean & Percentage (\%) & \\
\hline 1. & 2.75 & 43.75 & \\
\hline 2. & 1.00 & $0 \%$ & \\
\hline 3. & 2.75 & 43.75 & \\
\hline 4. & 1.75 & 19 & \\
\hline 5. & 1.25 & 6.26 & \\
\hline 6. & 1.75 & 19 & \\
\hline 7. & 1.25 & 6.25 & \\
\hline 8. & 1.5 & 12.5 & \\
\hline 9. & 3.25 & 56.25 & \\
\hline 10. & 3.75 & 68.75 & \\
\hline 11. & 1.5 & 12.5 & \\
\hline 12. & 2.75 & 43.75 & \\
\hline 13. & 1.25 & 6.25 & \\
\hline 14. & 2.5 & 37.5 & \\
\hline 15. & 2.75 & 43.75 & Formulae used, \\
\hline 16. & 1.5 & 12.5 & $\%=($ Mean -1$) \times 25$ \\
\hline 17. & 1.5 & 12.5 & \\
\hline 18. & 2.5 & 37.5 & \\
\hline 19. & 1.75 & 19 & \\
\hline 20. & 2.75 & 43.75 & \\
\hline 21. & 1.75 & 19 & \\
\hline 22. & 2.5 & 37.5 & \\
\hline 23. & 0.75 & 6.75 & \\
\hline 24. & 2.75 & 43.75 & \\
\hline 25. & 1 & 0 & \\
\hline 26. & 3 & 50 & \\
\hline 27. & 2.5 & 37.5 & \\
\hline 28. & 3.75 & 68.75 & \\
\hline
\end{tabular}




\begin{tabular}{|l|l|l|l|}
\hline 29. & 2.75 & 43.75 & \\
\hline 30. & 1.25 & 6.25 & \\
\hline 31. & 2.25 & 31.25 & \\
\hline 32. & 3.5 & 62.5 & \\
\hline 33. & 3.25 & 56.25 & \\
\hline 34. & 3.5 & 62.5 & \\
\hline 35. & 2.5 & 37.5 & \\
\hline 36. & 2.75 & 43.75 & \\
\hline 37. & 2.25 & 31.25 & \\
\hline 38. & 1 & 0 & \\
\hline
\end{tabular}

OVERALL MEAN $=1.23$

OVERALL PERCENTAGE $\quad=30.75 \approx 31 \%$

SOURCE - Reading in Human Resource Development by T.V. Rao, Published Oxford \& IBH publishing Co. Pvt. Ltd. Delhi, Calcutta.

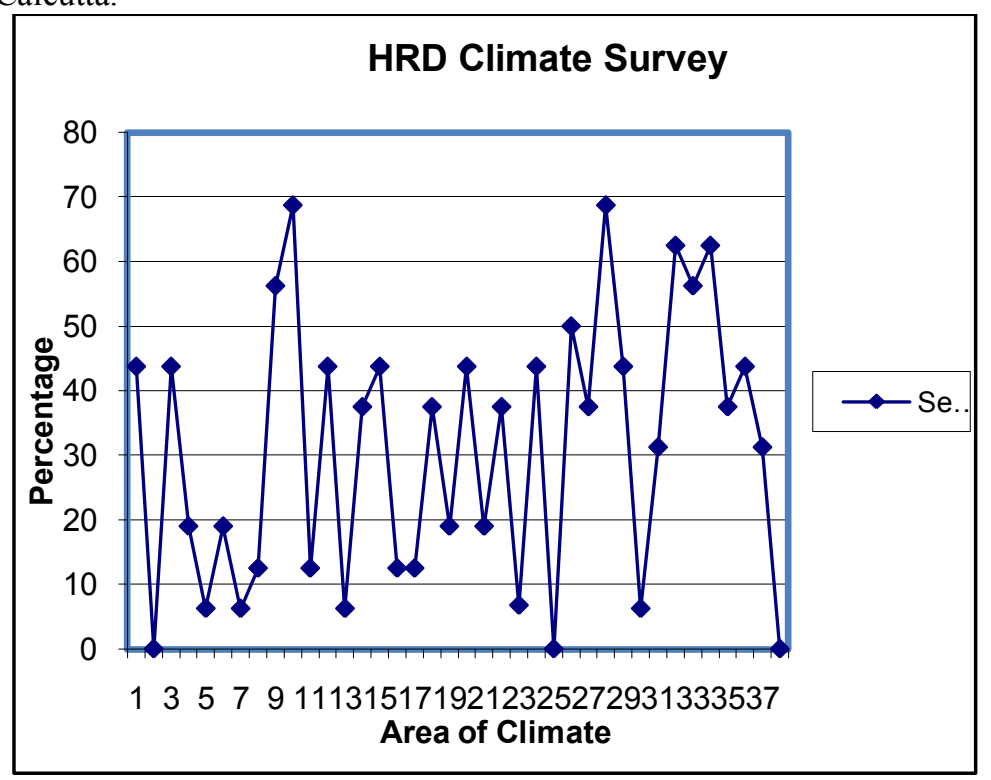

V. Limitation Of The Study:

* The study was conducted in Bhubaneswar, Odisha in UCO Bank which may not reflect exact figure.

* Period was also limited.

* Size of the sample was also very small.

\section{Recommendations:}

To have an overall improvement in UCO Bank the following steps should be taken.

* Necessary changes should be introduced and new HR Policies and Practices should be adopted.

* The officers should not be restricted to offer their views without any fear.

- A feedback from the officers at regular intervals should be obtained to find out the short comings.

* The officers should be encouraged to contribute their best by way of recognition, rewards \& prizes etc.

* Team spirit is essential for a healthy HRD climate.

\section{Conclusion}

HRD climate plays a vital role in the success of any organization because it directly or indirectly effect the performance of employers/officers.

Any organization that would like to be dynamic and growth oriented has to pay attention to the development of its human resources. People must be continuously helped to acquire capabilities for effective performance of new roles/functions/tasks that may arise in the process of organizational dynamism and growth. In the recent past, mechanisms like performance appraisal, counseling, OD, potential appraisal, job enrichment have been introduced in various organizations. A minimal positive developmental climate is essential for the success of these programmes. This survey is to find out the extent to which such developmental climate exists in the organisation.

If HRD climate is good the employees/officers will contribute maximum for the achievements of the organizational objective. The study shows HRD climate in UCO Bank is average and there is plenty of scope for 
its improvement. The management should improve the HRD climate by introducing various changes in HR Policies \& Practices.

\section{Acknowledgment}

The author wishes to express heartiest gratitude and indebtedness to Dr. Kalyan Kumar Sahoo, Professor Mahendra Institute of Management \& Technological studies Bhubaneswar, Odisha, India, \& Dr. Ayasa Kanta Mohanty, Associate. Professor, Institute of Business \& Computer Science, S.O.A., Bhubaneswar, Odisha, India who gave insightful guidance, sustained encouragement and help in Publishing the Article. Without their help, the preparation of the article would not have been possible.

\section{References:}

[1]. Banu,(2007) conducted study in public sector Cement Corporation in Tamil Nadu and found that the sound HRD climate is necessary for the success of public sector undertaking.

[2]. Srimannarayanna M,(2007) conducted a study in local bank of Dubai and found that a good (HRD) climate was prevalent in the organization. He found out the differences in perception of employees regarding the HRD climate on the basis of demographic variables.

[3]. Mufeed \& Gurkoo (2006)attempted to study whole gamut of HRD climate in universities and other equivalent higher level academic institutions by eliciting employee perceptions on HRD climate for which the University of Kashmir,Srinigar is selected as the main focal point of study.

[4]. Mufeed SA,(2006)examined the HRD climate in major hospitals. The result indicated the existence of poor HRD climate in the hospitals.

[5]. Sampath \& Kalpana,(2005)conducted a study and found that to a large extent organizations where knowledge workers work a 'good' HRD climate. The strengths of the HRD Climate emerges from the organization's belief that the human factor is a critical factor and need commitment to development, team spirit, helpfulness and providing training on skills and knowledge. The result indicated the presence of psychological climate conducive for development.

[6]. Venkateswaran,(2002)made study in a public sector undertaking in India and found that to a large extent, a favorable HRD Climate was prevalent in the organization.

[7]. Bhardwaj\& Mishra,(2002)examined the HRD Climate in private sector organization. The result showed the existence of Good HRD climate in the organization. The managers were satisfied with the HRD policies and practices of the organization.

[8]. Alphonsa,(2000)conducted a survey to examine the HRD climate of private hospital. The responses were collected from different departments in the hospital. The researcher found that the perception of the supervisors about the HRD climate is satisfactory and reasonably good climate was prevailing in the hospital.

[9]. Sharma and Purang,(2000)conducted a study and found out the relationship between value institutionalization and HRD climate in engineering and manufacturing sector and found the positive relationship between the two variables.

[10]. Krishna and Rao,(1997)carried out a comprehensive empirical study in BHEL, Hyderbadad and found that HRD climate in the organization encouraged Middle and Senior Level Managers.

[11]. Rao and Abraham,(1986)found that the general HRD climate organization appears to be at an general level.

[12]. Shuncagel, Betty Lou,(1976)studied the Human relations motivational structures of individuals in small work groups and their supervision Mach Harold Dennis,(1976) researched on the self-monitoring of Expressive Behavior in Human Relations groups.

[13]. Wooten-Trott, Hollister,(1976)studied on "An analysis of a human relations training programme for managers and supervisors".

[14]. Malzon, Don Edwin,(1975)investigated into how Human values are affected by an individual's perceptions of his work organization, Durangonzaliz. Lilia Irene,(1977) studied on the value of choice in Human Behavior.

[15]. Md. Abbas Ali,(1978)investigated into the expected job attractiveness and satisfaction on information integration.

[16]. Chattopadhyay, Nishith Ranjan,(1970) studied some psychological problems of middle level executives in selected large scale undertakings in India.

[17]. Van Duren, Allan,(1976)studied on the value of Performance Appraisal in the motivation of Engineering Personnel.

[18]. Hadery, Sharnoyela,(1975)researched into the Management job in large contemporary bureaucratic organization-Do managers perceive it as satisfying? An application of the motivation-"Hygiene theory to Management Job".

[19]. Solomon, Robert James,(1975) studied on the importance of manager subordinate perceptual differences to the study of leadership.

[20]. Amarsingh,(1985)studied the correlations of job satisfaction among different professionals. 